\title{
Semaphorins and tumor angiogenesis
}

\author{
Guido Serini · Federica Maione $\cdot$ Enrico Giraudo • \\ Federico Bussolino
}

Published online: 27 May 2009

(C) Springer Science+Business Media B.V. 2009

Erratum to: Angiogenesis

DOI 10.1007/s10456-009-9138-4

3rd Author was erroneously missed out.

The online version of the original article can be found under doi:10.1007/s10456-009-9138-4.

G. Serini $(\bowtie) \cdot$ F. Maione $\cdot$ E. Giraudo · F. Bussolino $(\square)$ Institute for Cancer Research and Treatment, 10060 Torino, Candiolo, Italy

e-mail: guido.serini@ircc.it

F. Bussolino

e-mail: federico.bussolino@ircc.it

G. Serini · F. Maione - E. Giraudo · F. Bussolino

Department of Oncological Sciences, University of Torino,

10060 Torino, Candiolo, Italy

e-mail: federico.bussolino@unito.it 